\title{
The Herzl Patient Health Information Service: An innovative solution to the problem of informing patients in primary care
}

\author{
Francesca Frati
}

\section{Introduction}

The Herzl Patient Health Information Service was intended to address known difficulties of informing patients in primary care, namely time, tools, and training [1-3]. The addition of a health information professional (HIP) to the healthcare team reduced the burden of informing patients for health professionals (HP), facilitated access to resources, and provided instructional support.

Patients and families who receive information are better able to participate in healthcare decisions and have improved health outcomes and increased satisfaction with their care [4-14]. A proliferation of online health information makes it difficult for patients and families to navigate to the most reliable and up-to-date information. Low literacy and health literacy ${ }^{1}$ as well as lack of the internet can be barriers to accessing information [7, 16-18]. Language and culture are further confounding factors [7, 19-21]. HPs may not have the time, know where to look for consumer health information, and (or) are not always trained or able to identify patient needs and preferences regarding decision-making or information [2, 14, 22].

HIPs have been developing and providing access to consumer health information for at least 40 years [23-28]. Recent trends see HIPs moving away from the traditional library environment towards meeting the needs of our users in the field [29-33], although our role continues to be relatively peripheral to the HP-patient dyad. HIPs must work to become fully integrated into the healthcare team by establishing for ourselves a trusted role alongside HPs and by engaging with patients at the point-of-care. Patient-centred care and shared decision-making, with their emphasis on information exchange, would benefit from the participation of HIPs at the point-of-care.

The Herzl Family Practice Centre is a family medicine clinic and a site for clinical training in family medicine office practice at the McGill-affiliated Jewish General Hospital in Montreal. In the past, a nurse with some hours devoted to patient education and a hospital library with a patient resource centre were not, in themselves, sufficient to address patients' information needs. Further, in the gap between Herzl's previous patient education initiative and the pilot in question, the patient education nurse had retired, the "pamphlet room" had been appropriated by the clinic for other purposes, and a pamphlet database developed by the library had fallen into disuse due to lack of online access and a cumbersome search interface. Few Herzl staff members were aware of the library or the Patient and Family Resource Centre (PFRC). To revitalize the Herzl's patient education initiative and address patient information needs, a pilot was implemented that embedded an HIP at point-of-care with access to library and PFRC resources. In this paper, this initiative and the barriers that impeded full integration are described.

\section{Description}

The pilot was implemented in three phases: (1) needs assessment: identifying the problem and assessing actual needs, (2) claiming dedicated space, and (3) integrating the HIP into patient flow.

\section{Phase 1: needs assessment}

A needs assessment was conducted in the summer of 2006. Two questionnaires were created and administered, one for patients and families $(N=81)$ and one for HPs $(N=18)$. The results showed that while patients and families were satisfied with their overall care, there was a desire and need for more health information. HPs felt that they would like patients to receive more information and, as expected, barriers included lack of time and unfamiliarity with consumer health resources.

Given that a nurse was no longer dedicated to patient education and that location and limited staffing ${ }^{2}$ had previously prevented the library and PFRC from fully addressing the information needs of Herzl patients, integrating an HIP at point-of-care was proposed as a viable solution. A

F. Frati. Health Sciences Library A-200, Jewish General Hospital, 3755 Cote-St-Catherine, Montreal, QC H3T 1E2, Telephone:

514-340-8222 x2438, e-mail: ffrati@jgh.mcgill.ca.

${ }^{1}$ A 2003 survey of Herzl patients found them more literate than expected [15].

${ }^{2}$ The library was in a distant pavilion and the Chief Medical Librarian was the only professional librarian on staff at this time. 
literature review revealed a single example in the United Kingdom that could be used as a precedent [32, 34].

\section{Phases 2 and 3: implementation}

The Herzl Patient Health Information Service opened in July 2007 at 7 hours per week. It served approximately 277 patients, 87 physicians, 10 nurses, and 4 allied health professionals over 39 months. A room dedicated to the service was made possible by a move to a larger facility (Appendix 1).

Consults were either direct, with the HIP interacting with the patient either in person or by telephone and (or) e-mail, or indirect, with the information being given to the HP who then passed it on to the patient. InfoRx referral pads were placed in all examination rooms (Appendix 2). To facilitate referrals, each sheet included a checklist of the most common family medicine topics. A profile for the HIP was added to the Herzl's appointment software so that consults could be booked by the team coordinators and counted as patient visits. However, it proved difficult to ensure that each team coordinator was aware of the service, the HIP's schedule, and the booking process. Given the limitations posed by hours on-site and ad hoc management coordination, most consults came from early adopter HPs [35] or directly from patients who became aware of the service through brochures and (or) the PFRC website (www.jgh. $\mathrm{ca} /$ pfrc). More buy-in was achieved once the HIP began participating in the teaching rooms, as described below.

Consults included a reference interview to determine the patients' real information needs. Needs were often discovered that were not included in the original InfoRx. Special needs such as information that was easy to read or advanced and (or) in multiple languages and preferred learning style were also determined. Searching was conducted when possible in front of the patient with an explanation of why certain resources were recommended, how to find them again from home, and how to evaluate health information using HonCode principles [36]. When the explicit purpose of the consult was to assist the patient with a difficult decision, decision aids were provided. ${ }^{3}$ A search for medical literature was conducted for patients with an advanced understanding of their condition and a demonstrated high level of health literacy. Consults lasted from 5 minutes to 1 hour depending on the nature of the question and the information needed and were documented in the patients' chart (Appendix 3). Questions coming from HPs were also documented. The most common requests for patient information were for information on immunization, prenatal care, and nutrition, suggesting that an HIP can support preventive healthcare.

A family medicine section of the PFRC website directed patients to reliable online information, as did handouts on the most common family medicine topics. The website received approximately 350 visits per month, ${ }^{4}$ the top three topics being vaccinations, breastfeeding, and pregnancy and prenatal testing. Handouts covered the following topics: prenatal screening, pregnancy, teen health, exercise, menopause, heart health, mental health, infant and child care, pain management, diabetes, and breastfeeding.

Following a 2008 RCT [31] that showed that a just-intime clinical support service by librarians in primary care improved decision-making, reduced costs, and saved clinicians' time, the Herzl initiative was extended to include a clinical medical librarianship (CML) component. Half of the 7 hours per week of the HIP were now spent in a teaching room with the supervising family physician(s). Being able to observe residents' interactions with their patients in real time via digital camera and hear residents present cases to the supervisors ${ }^{5}$ allowed the HIP to better identify and meet patient information needs. In this new capacity the HIP was also able to answer clinical queries and help residents use EBM resources such as point-of-care tools e.g., Essential Evidence Plus and Dynamed ${ }^{6}$. A presence in the teaching rooms was the most effective means of building trust and integrating the HIP fully into the team.

Due to increased requests for pamphlets by HPs, a library student was hired for 3 hours per week in the last year of the pilot to manage orders and work with the HIP to develop a classification system for the collection. It was decided that a simplified version of the Planetree Classification System would provide a structure that was easy to browse for HPs and patients alike [37]. The system had not yet been implemented when the pilot ended.

\section{Outcomes}

The above-outlined model was successful for several reasons: (1) it raised awareness about the importance of informing patients and and (2) it increased the amount of information received by patients. The service was integrated into residents' practice and there was a marked increase in the demand for pamphlets. The advocacy for and support of a few HPs, plus the addition of a CML component, were the key elements in shepherding the service but were not enough to integrate the HIP fully into the health care team, for reasons discussed below.

A patient satisfaction survey was conducted by the PFRC in 2009-2010 that included the pilot. The small sample, although anecdotal, points to an increased level of patient engagement and satisfaction. In an informal survey of Herzl HPs in 2008, HPs who used the service felt that it helped patients reflect on their illness, treatment, and selfcare skills and that the burden to inform patients was lightened. It was difficult for HPs to recognize which patients could benefit from the service or how to refer their patients, possibly because an exchange of information was not appropriate for every patient or visit [14, 22].

\footnotetext{
${ }^{3}$ The most often requested decision aids were for prostate cancer treatment and screening. The HIP was also asked to create an extensive annotated bibliography of recent evidence on the controversial topic of PSA screening for prostate cancer in order to help HPs decide whether to recommend it.

${ }^{4}$ Calculated over a 16 month period from the time of the new hospital website on 15 June 2009 to 30 September 2010

${ }^{5}$ With approval from the hospital's Clinical Ethics Office.

${ }^{6}$ The residents were already familiar with UpToDate and an effort was made to expand their use of other tools.
} 


\section{Discussion}

Selling the service and integrating it into the management process and into patient flow proved to be the greatest challenges for the pilot. HPs behaved according to Rogers' bell curve ${ }^{7}$ regarding the diffusion of innovations [35], with a few HPs adopting early and many slow to change. Without a formal process of integration, no future pilot can be a precursor to implementing a service in the long-term. "Formal" could be as little as a memo of introduction and inclusion in the team contact information sheet. Unless the HIP is visibly integrated into the health care team and process, issues of trust and even territoriality can prevail. For example, some nurses were slow to adjust to the idea of having an HIP involved with patient education; physicians were likely to see the benefits of having an HIP participate in patient-care, but were not always able to identify who could benefit from the service, nor did they always remember to refer their patients - again, an issue of process management. A better understanding of change management on the part of the HIP and more formal support from management may have allowed for an effective resolution of the above issues and concerns. Residents and resident supervisors were the most enthusiastic adopters of the service and were more aware of the importance of informing their patients as time went on, having benefitted from the example of the HIP who was able to point out opportunities for information exchange as they arose. Increased awareness may also have been influenced by a growing emphasis on patient education and patient-centred care in medical school curricula.

A good pilot must be properly provisioned or ruthlessly focused. Although in this case, the late addition of a CML service proved inspired, this left only 3.5 hours per week to develop the website and handouts, conduct additional consults, manage the pamphlet collection (resulting in the need to hire a student), promote the service, provide lectures to residents, and administrative varia.

Extensive reading of the medical literature and recognizing the problem as one of knowledge translation were crucial to the success of the project. In addition to the usual methods of promotion - presentations, a brochure, and the website - the use of brief evidence summaries proved to be effective. An evidence summary showing that language can be a barrier to patients' understanding [38] resulted in a consistent increase in requests for information in multiple languages.

Since the pilot ended, Herzl HPs are welcome to refer their patients to the HIP at the PFRC, although not many have done so. The HIP is also available to conduct literature searches and answer clinical queries and has received several requests. Use of the website has increased ${ }^{8}$ and the HIP continues to maintain it. The library student remained at the clinic to manage the pamphlet collection for several months after the end of the pilot. It is not certain whether the library student will be replaced, although use of the pamphlets remained consistently high until her departure. There are no current plans to reinstate the service.

\section{Conclusion}

This pilot suggests that an HIP can be a valuable member of the healthcare team at point-of-care, ensuring that informing patients becomes a regular part of the continuum of care. However, a bolder initiative is required, one that fully integrates the HIP into the management process and patient flow. Working knowledge of the principles and process of change management on the part of the HIP is an essential component, and information studies curricula should continue to evolve in order to reflect increased participation in and leadership of interdisciplinary teams and field work by graduates. The specific role that HIPs can play in patient-centred care and shared decision-making is worth study; furthermore, the real impact of a health information service at point-of-care would benefit from a more formalized evaluation process.

\section{Reference List}

1. Légaré F, O’Connor AM, Graham ID, Saucier D, Côté L, Blais J, et al. Primary health care professionals' views on barriers and facilitators to the implementation of the Ottawa Decision Support Framework in practice. Patient Education Counseling. 2006;63(3):380-90.

2. West E, Barron D, Reeves R. Overcoming the barriers to patient centred care: time, tools and training. J Clin Nursing. 2005; 14(4):435-43.

3. O'Donnell S, Cranney A, Jacobsen MJ, Graham ID, O'Connor AM, Tugwell P. Understanding and overcoming the barriers of implementing patient decision aids in clinical practice. J. Evaluation Clin Practice. 2006;12(2):174-81.

4. Adams RJ. Improving health outcomes with better patient understanding and education. Risk Manage Healthcare Policy. 2010;361:-72.

5. Coulter A. Cancer Reform Strategy Patient Experience Working Group. Evidence on the effectiveness of strategies to improve patients' experience of cancer care. Picker Institute 2007.

6. Coulter A, Parsons S, Askham J. Policy brief: where are the patients in decision-making about their own care. World Health Organization; 2008. Available from: http://www.who. $\mathrm{int} /$ management/general/decisionmaking/WhereArePatientsin DecisionMaking.pdf.

7. Edwards M, Davies M, Edwards A. What are the external influences on information exchange and shared decision-making in healthcare consultations: a meta-synthesis of the literature. Patient Education Counseling. 2009;75(1):37-52.

8. Epstein RM, Alper BS, Quill TE. Communicating evidence for participatory decision making. JAMA. 2004;291(19):2359.

9. Department of Health. Better information, better choices, better health: putting information at the centre of health. Quarry Hill: Leeds;2004.

10. Joosten E, DeFuentes-Merillas L, De Weert G, Sensky T, Van der Staak C, De Jong C. Systematic review of the effects

${ }^{7}$ Innovators, early adopters, early majority, late majority, laggards.

${ }^{8}$ From approximately 350 visits to approximately 450 visits per month. 
of shared decision-making on patient satisfaction, treatment adherence and health status. Psychother Psychosomatics. 2008;77(4):219-26.

11. Jordan JL, Ellis SJ, Chambers R. Defining shared decision making and concordance: are they one and the same? Postgrad Med J. 2002 July 1, 2002;78(921):383-4.

12. Mahlmeister LR. Best practices in perinatal nursing: partnering with patients to enhance informed decision making. J Perinatal Neonatal Nursing. 2009;23(3):213.

13. Woolf SH, Chan ECY, Harris R, Sheridan SL, Braddock CH, Kaplan RM, et al. Promoting informed choice: transforming health care to dispense knowledge for decision making. Ann Internal Med. 2005 August 16, 2005;143(4):293-300.

14. Gravel K, Légaré F, Graham I. Barriers and facilitators to implementing shared decision-making in clinical practice: a systematic review of health professionals' perceptions. Implementation Sci. 2006;1(1):16.

15. Smith J, Haggerty J. Literacy in primary care populations: is it a problem? Can J Public Health. 2003;94(6):408-12.

16. Nutbeam D. The evolving concept of health literacy. Social Sci Med. 2008;67(12):2072-8.

17. Burnham E, Peterson EB. Health information literacy: a library case study. Libr Trends. 2005;53(3):3.

18. Salzburg Global Seminar. Salzburg statement on shared decision making. Br Med J. 2011;342.

19. Chen AH, Jacobs EA, Endowment C. Language barriers in health care settings: an annotated bibliography of the research literature. California Endowment; 2003.

20. Karter AJ, Ferrara A, Darbinian JA, Ackerson LM, Selby JV. Self-monitoring of blood glucose: language and financial barriers in a managed care population with diabetes. Diabetes Care. 2000;23(4):477.

21. Zanchetta MS, Poureslami IM. Health literacy within the reality of immigrants' culture and language. Can J Public Health. 2006;97(2):26.

22. Légaré F, Ratté S, Gravel K, Graham ID. Barriers and facilitators to implementing shared decision-making in clinical practice: update of a systematic review of health professionals' perceptions. Patient Education Counseling. 2008;73 (3):526-35.

23. Deering MJ, Harris J. Consumer health information demand and delivery: implications for libraries. Bull Med Libr Assoc. 1996;84(2):209.

24. Eakin D, Jackson SJ, Hannigan GG. Consumer health information: libraries as partners. Bull Med Libr Assoc. 1980;68(2):220.
25. Harris CL. Hospital-based patient education programs and the role of the hospital librarian. Bull Med Libr Assoc. 1978;66 (2): 210 .

26. Miller N, Lacroix EM, Backus JEB. MEDLINEplus: building and maintaining the National Library of Medicine's consumer health Web service. Bull Med Libr Assoc. 2000;88(1):11.

27. Nolan ME. Have consumer health websites, will travel: taking patient education information to physicians' offices. $J$ Hosp. Librarianship. 2008;8(3):358-65.

28. Voge S. NOAH - New York online access to health: library collaboration for bilingual consumer health information on the Internet. Bull Med Libr Assoc. 1998;86(3):326.

29. Cimpl K. Clinical medical librarianship: a review of the literature. Bull Med Libr Assoc. 1985;73(1):21.

30. Johnson BL, Alexander LA. In the field: an innovative role puts academic librarians right in the departments they serve. Libr J. 2007;132(2):3.

31. McGowan J, Hogg W, Campbell C, Rowan M. Just-in-time information improved decision-making in primary care: a randomized controlled trial. PloS one. 2008;3(11):3785.

32. Wilson D, Bateman H, Bailey P. Early experience of the contribution of an information specialist within a primary healthcare team. J Librarianship Inf Sci. 2004;36(3):127.

33. Rose DB. Role of a medical librarian in the DaVinci Project, a patient-centered IT supported healthcare team clinical approach in primary care. Canadian Health Libraries Association Conference; 200930 May - 3 June; Winnipeg; $J$ Can Health Libr Assoc. 2009;30(3):98.

34. Grimwood D. Getting health information into communities. Inf Update. 2004;3(12):22-5.

35. Rogers EM. Diffusion of innovations. 5th ed: Simon and Schuster; 2003 [cited 22 Apr 2011]. Available from http:// books.google.ca.

36. Health On the Net Foundation. The HON Code of Conduct for medical and health Web sites (HONcode). 2010 [updated 26 March 2010; cited 20 March 2011] [Information policies and management: Health On the Net Code of Conduct (HONcode) devoted to medical and health Web sites]. Available from http://www.hon.ch/HONcode/Conduct.html.

37. Cosgrove TL. Planetree health information services: public access to the health information people want. Bull Med Libr Assoc. 1994;82(1):57.

38. Frati F. Health information in multiple languages at Herzl [evidence summary] 2009. Available from: http://205.237. 250.153/SITES/004-01-health-sciences-library/Herzl/Evidence $\% 20$ summary $\% 201$ language $\% 20$ barriers.pdf. 


\section{Appendix 1}

Floor plan for the pilot aka Herzl Health Information Service (H-PHIS).

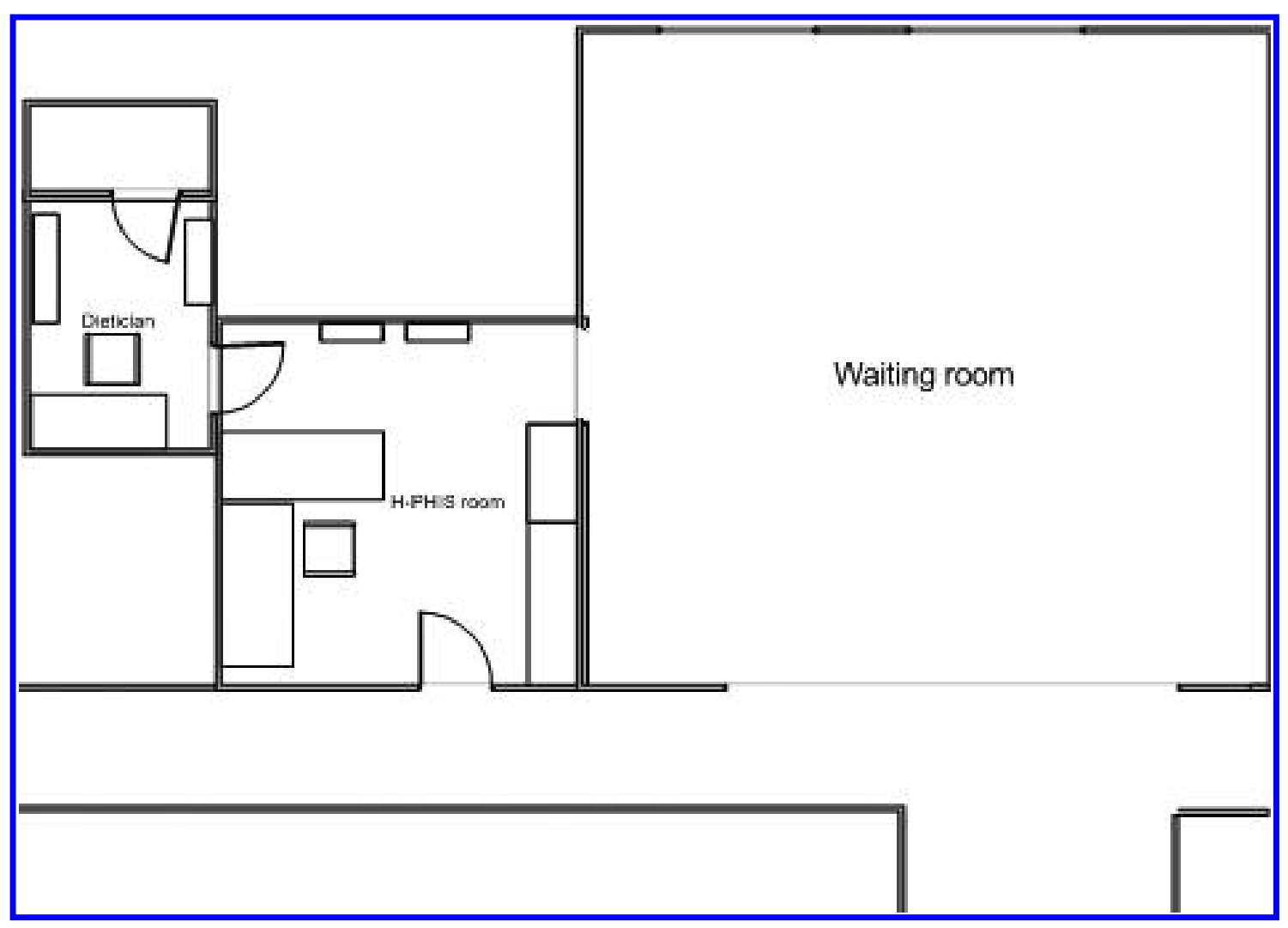




\section{Appendix 2}

Referral sheet.

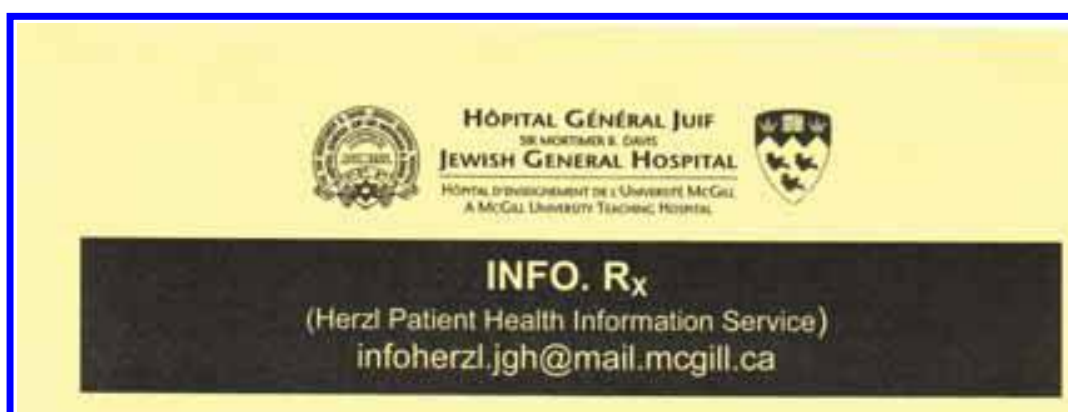

CHART \#

DATE:

REFERRING HEALTH CARE TEAM MEMBER:

Please provide information on:

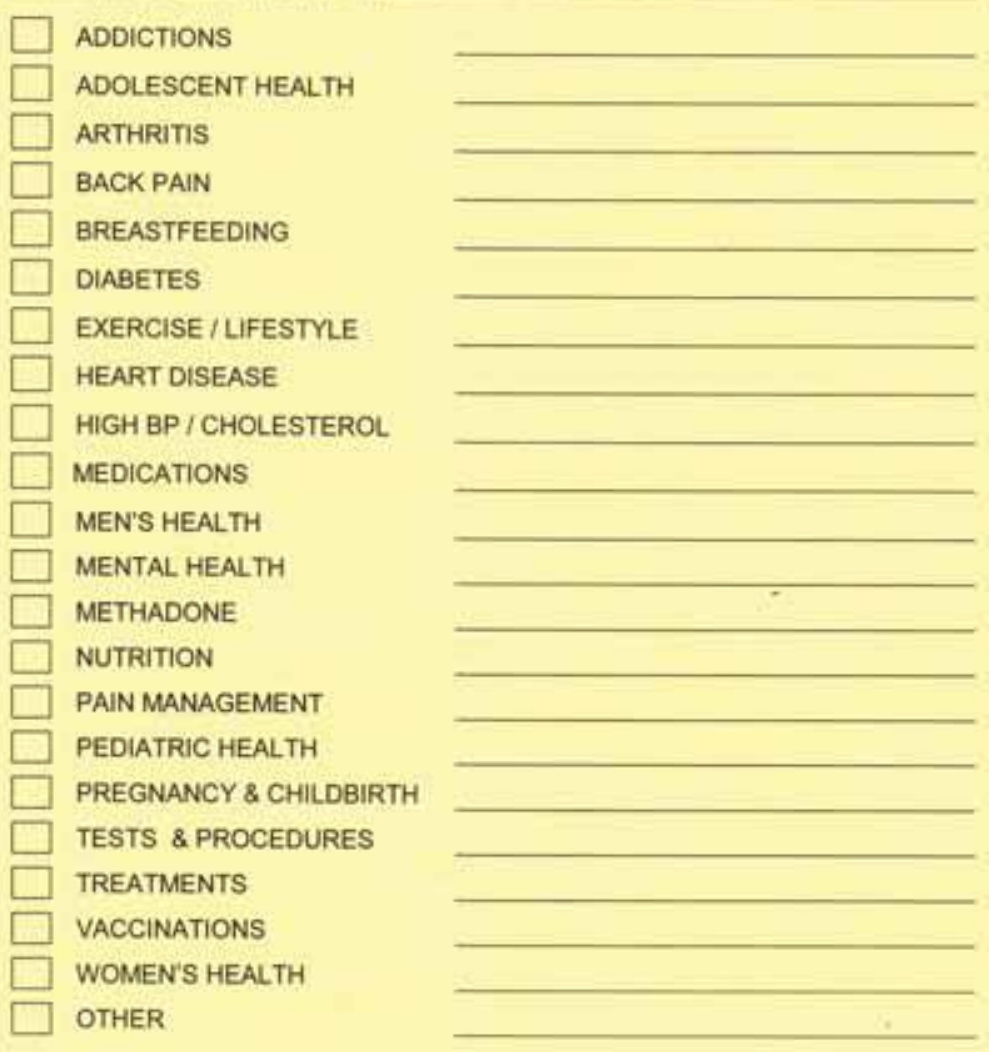




\section{Appendix 3}

Consult.

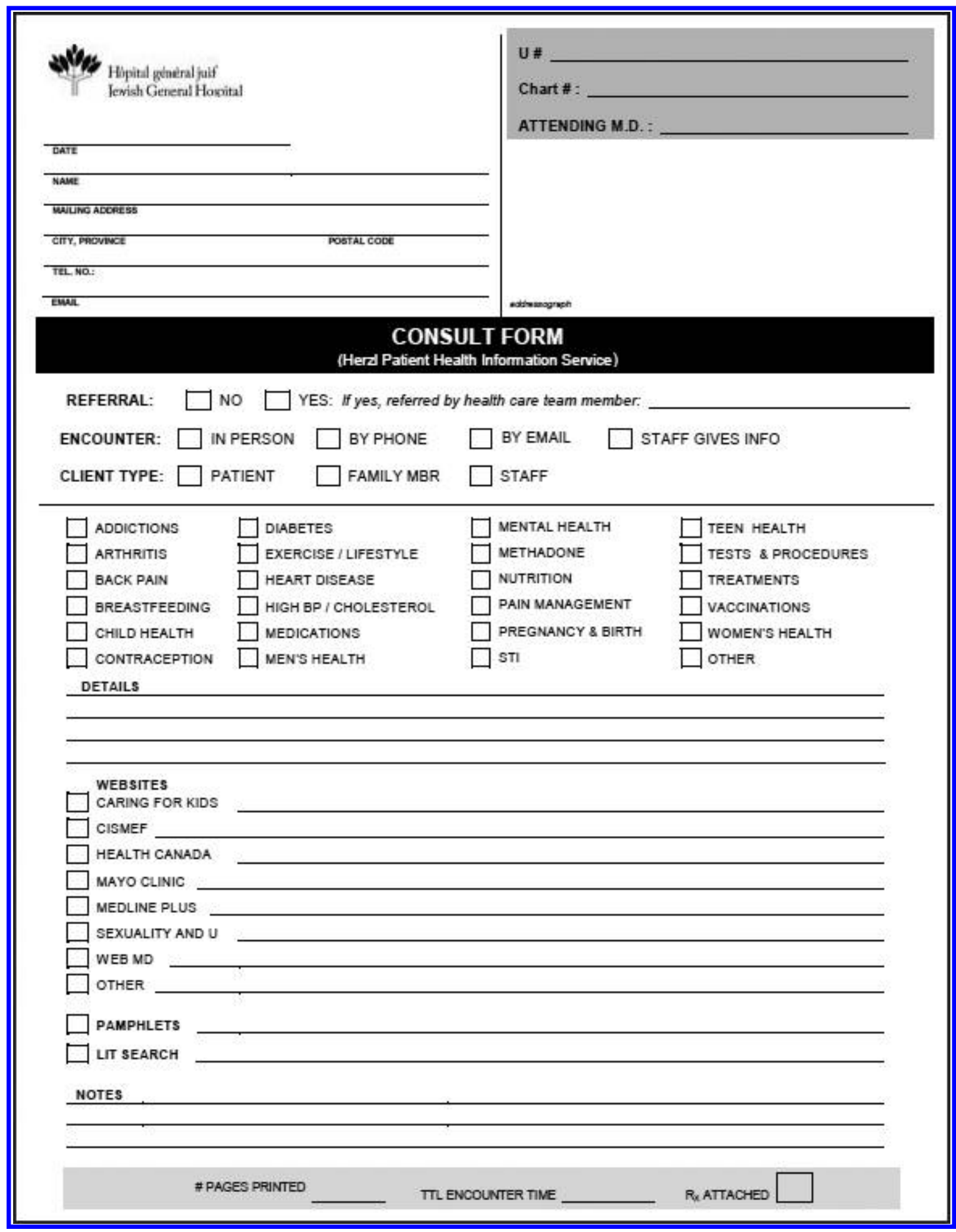

